\title{
The Consumers' perceptive of Internet-of-Things: Exploring Users' Acceptance and Purchase Behavior
}

\author{
Hui-Hsin Huang \\ Associate Professor, Department of Business Administration, Aletheia University, Taiwan \\ hoyasophia@gmail.com
}

\begin{abstract}
This paper stands on customer's view of point to discuss the usage on Internet of Things(loT). A purchase behavior model of loT is constructed based on ChaCha model to explore the impact factors that influence customer's adoption of IoT. The characteristics of loT itself and customer individual characteristics are also included. Then a survey data will be conducted to estimate the parameters of the proposed model. These empirical data are also used to make model calibration. Finally, the application of loT in marketing management will be present in the conclusion.
\end{abstract}

Keywords: Internet-of-Things(IoT), purchase behavior, ChaCha model

\section{Introduction}

The Internet of Things (IoT) promises a new technological paradigm(Luet al.,2018), when everyday objects can be augmented with RFID tags and intelligent sensors to become ICCs, real-time data flow can be automatically produced. This trend can improve marketing research into new broad areas (Ngand Wakenshaw, 2017).

Previously physical product consumption would occur in consumers' private spaces, an era of loT would user in a substantial amount of quantitative data on consumption and experience (Ngand Wakenshaw, 2017). This would create a dimension of visibility where none had previously existed, particularly with information on consumption quantity and depletion for particular contexts, interactions between things and between people and things, and information about the environment (Parry et al., 2016).

IoT offers products with various functions and target scope. In the business literature, these characteristics have a significant impact on consumer purchase intention and good-practice principles in product design. Therefore, the purpose of this paper is to explore the loT adoption or purchase intention of customers and the relationships of its impact factors. This research will construct a model to use these factors to predict the probability of customers' loT purchase intention (adoption).

\section{IoT and Customers' Purchase behavior}

There are other researches (Bao et al., 2014; Gao and Bai, 2014; Chang et al.2014;Rau et al., 2015) find that the customers 'experience is the mediator variable which can mediate the effect between loT characteristics and purchase intention.

DOI: $10.14738 /$ tnc. 75.7535

Publication Date: $15^{\text {th }}$ December 2019

URL: http://dx.doi.org/10.14738/tnc.75.7535 
Hui-Hsin Huang; The Consumers' perceptive of Internet-of-Things: Exploring Users' Acceptance and Purchase Behavior, Transactions on Networks and Communications, Volume 7 No. 5, October (2019); pp: 13-17

Customers' experiments of loT can be divided into functional experience and emotional experience. The marketing activities such loT promotion, product design and management can focus on these experiences to facilitate customers' purchase intention. Thus, this paper combines the characteristics of loT itself and customer individual characteristics to formulate a model to predict the purchase intention that customer's adoption of loT.

The paper is constructed into four parts. Firstly, we make a literature review to demonstrate the purchase intention model of customer's adoption of loT. In this part, the ChaCha model (Wang,2014) and its literature is introduced. The previous researches of impact factors on customer's adoption of loT which include characteristics of IoT and customer individual characteristics are also reviewed. Secondly, the empirical data is used to make parameters estimation and model calibration. In this part, the method of data collection and analysis are present. The theory background of questionnaires is introduced. Thirdly, the results of parameters estimation and model calibration are shown. Finally, the conclusion is made.

\section{The theory background of Model}

In this research, we based on the concept of ChaCha model (Wang,2014) which combinesthe motivated media processing and selective exposure behavior to discuss the TV viewing experiment and channel choice behavior. In the literature review, we can find that the impact factors of customers' loT adoption or purchase can be attributed to their motivation. ChaCha model includes the audience's motivation value and motivation strength to forecast viewing behavior. Thus, we use the framework of ChaCha model to portray the customer's loT purchase behavior.

Based on Wang (2014), we propose that the customers' purchase intention of loT $(p)$ is a random variable which is following the Wald distribution(inverse Gaussian) with its probability density function(pdf),

$$
f(p)=\left(\frac{\sigma}{2 \pi p^{3}}\right)^{\frac{1}{2}} \exp \left[-\frac{\sigma(p-\delta)^{2}}{2 \delta^{2} p}\right]
$$

\section{Motivation}

Acoording to Chang et al.(2014), Lu et al.(2018), Rau et al.(2015), Kim and Kim, (2016), we can divide the motivation of customers' purchase intention of IoT into the characteristics of loT itself and customer individual characteristics.

\section{Customer individual characteristics}

We use $\alpha$ as the customer individual characteristics such as demographic variables orperceived usefulness and perceived ease of use. Thus, $\alpha$ is shown in equation (1) with $\delta=\alpha / \tau^{-1}=\alpha$ tand $\sigma$ isthe shape of the Wald distribution (Luce, 1986).

$$
\alpha=B_{0}+b_{1} \alpha^{\prime}{ }_{1}+B_{2} \alpha^{\prime}{ }_{2}+B_{3} \alpha^{\prime}{ }_{3}+\ldots+B_{n} \alpha_{n}^{\prime}
$$

in which $B_{1} \ldots B_{n}$ is the coefficient of $n$ individual characteristics.

T is motivational strength, $\tau(h)=\exp [m(h)]$, loT motivational values, which can range from negative (aversive motivational) to positive (appetitive motivational), are transformed by exponential transformation(Wang, 2014).Motivation strength will decay when time passing.

\section{Characteristics of IoT}

We propose $y$ is the characteristics of IoT which can attract customers to adopt are a linear equation as 


$$
m(h)=m(h-1)+a_{1} \gamma_{1}+a_{2} \gamma_{2}+a_{3} \gamma_{3}+\ldots+a_{k} \gamma_{k}
$$

in which $m(h)$ as the motivational value of IoT, which is the motivational value used to predict the $h$ th purchase after viewing all the previous $h-1$ occasions. There are $k$ characteristics of loT.

\section{Empirical data}

The empirical survey data are used to estimate the parameters of present model and make model calibration. We use survey ethod to collect the empirical data. The duration of survey is from 1 September to 31 October in 2019. There are 2416 sample sizes.

The questionnaire design is based on the previous theory background. For the loT factors, based on Chang et al.(2014) and Lu et al.(2018), there are six characteristics of loT which can influence the customers' purchase intention. They are (1) loT Convenience is "the degree to which consumers save time and effort in the process of planning, purchasing, and using a product".(2) loT Security is "damage avoidance when it comes to any vulnerable and valuable assets".(3) IoT Telepresence is "the subjective feelings of customers about the extent to which media represent the physical and social environment".(4) loT Intelligence is" intricate and accurate recognition functions, correct thinking and judgment capabilities". (5) IoT Connectivity is "the degree to which things are interconnected".(6) loT Interactivity is "the customers' feeling that occurs when information communication is bidirectional and response is timely". These items are measured by Likert five scales.

For customers' characteristics, the most used is technology acceptance model(Kim and Kim, 2016) in which perceived usefulness and perceived ease of use(Bao et al., 2014; Gao and Bai, 2014)to predict loT adoption. Lu et al.(2018) also mention that the customers' experience is the mediator variable which can mediate the effect between loT characteristics and purchase intention. And fun and enjoyment are obtaind in IOT function. Thus, we include perceived usefulness, perceived ease of use and customers' experience (fun and enjoyment) as three individual factors to influence the customers' loT purchase behavior. These items are also measured by Likert five scales.

\section{The Parameters estimation}

We divide the 2416empirical data randomly into two parts. One(1408 sample size) is for parameters estimation, another is for model calibration. For the questionnaires design, some parameters in model such as $n$ i ndividual characteristics are $n=4$ (there are four impact factors of individual characteristics in questionnaires design), $\mathrm{k}=6$ there are four impact factors of loT characteristics in questionnaires design) and $h=4$ (There are four duration of observing customer purchase occasions which are from 1September to 15 September, from 16 September to September 30, from 1 October to 15October, from 160ctober toOctober). The results of parameters estimations are shown in table 1.

Table 1 The results of parameters estimations

\begin{tabular}{|l|l|l|l|l|l|l|l|l|l|l|l|l|}
\hline & $b_{0}$ & $b_{1}$ & $b_{2}$ & $b_{3}$ & $b_{4}$ & $\gamma_{1}$ & $\gamma_{2}$ & $\gamma_{3}$ & $\gamma_{4}$ & $\gamma_{5}$ & $\gamma_{6}$ & $\sigma$ \\
\hline & 2.417 & 0.591 & 0.355 & 0.677 & 0.412 & 3.424 & 0.268 & 0.359 & 0.821 & 0.664 & 0.565 & 0.2 \\
\hline
\end{tabular}

The root-mean-square deviation(RMSD)( Busch et al., 2014) is used as model calibrationto calculate the real data and the data which is stimulated from using the results of parametersestimations. We denote $r_{d}$ is the real data, $s_{c}$ is the simulation data. To use the 2416 total sample sizes, we divide the whole samples 
Hui-Hsin Huang; The Consumers' perceptive of Internet-of-Things: Exploring Users' Acceptance and Purchase Behavior, Transactions on Networks and Communications, Volume 7 No. 5, October (2019); pp: 13-17

into two parts. Thus, $\mathrm{d}=1408$ and $\mathrm{c}=1408$. We calculate the average distance between $r_{d}$ and $s_{c}$. The result is shown as

$$
\frac{\sum_{d=1, c=1}^{1408} \sqrt{\left(r_{d}-s_{c}\right)^{2}}}{1408}=0.673
$$

The result of RMSD is $67.3 \%$ which is smaller than $70 \%$. It means the distance between real data and simulation data is not far. Therefore, the goodness of fit of the proposed model is acceptable.

\section{Conclusion and Discussion}

This paper proposes a probability model to predict customers purchase intention of loT. To merge the motivation concept into model construction, the author bases onthe business literature of loT to include the characteristics of both individual and loT to make the proposed model more useful. For marketing, managers can find which factors will have great impact on the customer's purchase behavior or what marketing strategies can be controlled to contribute customers to loT adoption. This proposed model combines the loT theory background such as technology acceptance model and probability calculation to make the theory more concert and more operational.

In the future, researchers can try to use other individual factors such as customers' demographic data to forecast the IoT adoption behavior. Beside the survey method, other research method such as experiment method also can be conduct to collect customers' psychological variables and find more customers' inside factors to approach loT use.

For the company side, the traits of IoT such as different functions can be included into the model to provide the reference for loT product design and make model more application.

\section{THE REFERENCE}

[1] Bao, H., Yee-Loong Chong, A., Ooi, K.-B., Lin, B.(2014). Are Chinese consumers ready toadopt mobile smart home? An empirical analysis.International Journal of Mobile Communications (Int. J. Mob.Commun.), 12(5), pp.496-511.

[2] Busch,P., Lahti,P. and Werner,R. F.(2014). Colloquium: Quantum root-mean-square error and measurement uncertainty relations.Reviews of Modern Physics, 86 , pp. 1261 $-1283$.

[3] Chang, Y., Dong, X., Sun, W.(2014). Influence of characteristics of the internet of things onconsumer purchase intention. Social Behavior and Personality: An International Journal, 42(2), pp. 321-330.

[4] Gao, L., Bai, X.(2014). A unified perspective on the factors influencing consumer acceptanceof internet of things technology.Asia Pacific Journal of Marketing and Logistics (Asia Pacific J. Market. Log.)26, pp.211-231. 
[5] Kim, S. and Kim, S. (2016). A multi-criteria approach toward discovering killer loT applicationin Korea. Technological Forecasting and Social Change(Technol. Forecast.Soc. Chang.), 102, pp.143-155.

[6] Lu,Y.,Papagiannidis, S. andAlamanos, E.(2018). Internet of Things: A systematic review of the business literature from theuser and organisational perspectives.Technological Forecasting \& Social Change ,136, pp.285-297.

[7] Luce, R. D. (1986). Response times: Their role in inferring elementary mental organization.New York, NY: Oxford University Press.

[8] Ng, C.L. I. and Wakenshaw, Y.L. S. (2017).The Internet-of-Things: Review and research directions. International Journal of Research in Marketing 34 ,3-21.

[9] Parry, G., Brax, S., Maull, R., \& Ng, I. (2016). OperationalisingloT for reversesupply: The development of use-visibility measures. Supply Chain Management: AnInternational Journal, $21(2), 228-244$.

[10] Rau, P.-L.P., Huang, E., Mao, M., Gao, Q., Feng, C., Zhang, Y.(2015). Exploring interactivestyle and user experience design for social web of things of Chinese users: a case studyin Beijing.International Journal of Human-Computer Studies, 80(8), pp.24-35.

[11] Wang, Z.(2014). Bridging media processing and selective exposure: a dynamic motivational model of media choices and choice response time.Communication Research, 41(8), pp.10641087. 